\title{
Endoscopic Findings and Associated Risk Factors in Primary Health Care Settings in Havana, Cuba
}

\author{
Enrique Galbán MD PhD, Enrique Arús MD PhD, Ulises Periles MD
}

\begin{abstract}
INTRODUCTION Upper gastrointestinal endoscopy, traditionally performed in Cuba in specialized hospitals, was decentralized to the primary health care level in 2004 to make it more patient-accessible.
\end{abstract}

OBJECTIVES Describe frequency and distribution of the principal symptomatic diseases of the upper gastrointestinal tract and their relation to the main risk factors associated with each in a sample of urban adults who underwent upper gastrointestinal endoscopy in primary care facilities in Havana in selected months of 2007.

METHODS A multicenter cross-sectional study was conducted, including 3556 patients seen in the primary health care network of Havana from May through November 2007. The endoscopies were performed at the 22 polyclinics (community health centers) providing this service. Diagnostic quality and accuracy were assessed by experienced gastroenterologists using a validated tool. Patients responded to a questionnaire with clinical, epidemiologic, and sociodemographic variables. Univariate and multivariate analyses (unconditional logistical regression) were used to identify associated risk factors. The significance level was set at $p<0.05$ (or confidence interval excluding 1.0).

RESULTS The diagnoses were: gastritis $(91.6 \%)$, duodenitis $(57.8 \%)$, hiatal hernia $(46.5 \%)$, esophagitis $(25.2 \%)$, duodenal

\section{INTRODUCTION}

In Cuba and most countries, prevalence studies of upper gastrointestinal $(\mathrm{Gl})$ tract diseases in the general population are virtually nonexistent; reports generally refer to frequency of these diseases in case series on endoscopies and hospital admissions, which are not representative of what actually occurs in the general population. In such studies, the diseases most commonly found are gastritis, peptic ulcer (both duodenal and gastric), hiatal hernia and gastric cancer.[1-5]

Availability of endoscopy at a primary care facility provides greater population access and thus enables earlier diagnosis of digestive tract diseases.[6] The international literature contains some evidence regarding endoscopic diagnosis performed at the primary care level-for example, in the United States and the United Kingdom, where the majority of procedures were done at the initiative of physicians in the public sector, but not as part of an integrated population-wide program. $[7-10]$ In this respect, the Cuban experience appears to be unique.

In the early years of the 21 st century, critical changes in the health sector have been introduced at all levels in Cuba. Of particular interest are changes in primary health care (PHC), where new technologies have been introduced to make diagnostic procedures more accessible, among them upper GI endoscopy.[6]

In 2004 the decision was made to offer upper GI endoscopy for diagnostic purposes in community-based polyclinics throughout Havana, to be extended later to those in the rest of the country. However, there were not enough endoscopists to materialize this ulcer $(15.8 \%)$, gastric ulcer $(6.2 \%)$ and malignant-appearing lesions $(0.4 \%)$. Overall prevalence of Helicobacter pylori infection was $58.4 \%$. The main risk factors for duodenal ulcer were $H$. pylori infection (OR 2.70, Cl 2.17-3.36) and smoking (OR 2.08, Cl 1.68-2.58); and for gastric ulcer, H. pylori (OR 1.58, Cl 1.17-2.15) and age $\geq 60$ years (OR $1.78, \mathrm{Cl} 1.28-2.47)$. H. pylori infection was the main risk factor for gastritis (OR 2.29, Cl 1.79-2.95) and duodenitis (OR 1.58, Cl 1.38-1.82); and age $\geq 40$ years for hiatal hernia (OR 1.57, Cl 1.33-1.84). External evaluation was "very good" or "good" for $99.3 \%$ of endoscopic procedures and $97.9 \%$ of reports issued.

CONCLUSIONS Gastrointestinal endoscopy performed in primary care yielded high quality results and important information about prevalence of the most common diseases of the upper GI tract and associated risk factors. This study provides a reference for new research and can inform objective recommendations for community-based interventions to prevent and control these diseases. The existence of a network of universally accessible diagnostic endoscopy services at the primary care level, will contribute to conducting further research.

KEYWORDS Endoscopy, gastrointestinal diseases, upper GI tract, prevalence, risk factors, primary care, Cuba

idea: at the time, there were some 200 gastroenterologist-endoscopists, only enough for performing the procedure in hospital. As a solution, family physicians were trained as endoscopists, creating a network of endoscopy services in PHC (Nodarse PO. Personal communication).

This study's objective is to describe the prevalence of the main upper $\mathrm{GI}$ tract diseases and their principal risk factors in patients seen in primary care facilities in Havana.

\section{METHODS}

Study design A multicenter cross-sectional study was conducted that included 3556 patients undergoing upper GI endoscopy in 22 endoscopy services at polyclinics in the 15 municipalities of Havana City province from May through November 2007. The National Gastroenterology Institute (IGE, its Spanish acronym) served as the study's coordinating center.

In the preparatory stage, training workshops were held on research methods and procedures to standardize diagnostic criteria and procedures. Participants included endoscopists, interviewers and senior management from each of the polyclinics involved.

The minimum sample size necessary for a simple proportion was calculated using the EpiTable calculator from Epilnfo 6.1, yielding a requirement for 3082 persons undergoing upper $\mathrm{Gl}$ endoscopy for the first time that year. Calculations assumed an estimated 10,000 endoscopies per year in Havana's PHC facilities, approximately 8000 of which would be performed on patients for the first 
time that year; a $5 \%$ prevalence of the least frequent disease; a $2 \%$ design effect; desired precision of $1.5 \%$; and a $95 \%$ confidence level $(\mathrm{Cl})$

Participant selection began in all settings on the same randomlychosen date in May 2007, and patients were consecutively added to the study over the next six months. The target number for each participating unit was 140 .

Inclusion criteria Patients aged $\geq 18$ years who had not previously undergone upper GI endoscopy that year.

Exclusion criteria Prior endoscopy that year; being monitored endoscopically or with conditions that could result in emergency endoscopies (e.g., gastroenterologic hemorrhage and ingestion of caustic substances or foreign bodies).

Study variables Dependent variables were clinical diagnoses of esophagitis, hiatal hernia, gastric ulcer, duodenal ulcer, gastritis, duodenitis, and malignant-appearing lesion. Independent variables are listed in Table 1. Height and weight were measured for calculation of body mass index (BMI).

Endoscopy The procedure was performed with Olympus (Japan) fiberoptic endoscopes, model GIF-E. Patient preparation consisted of a 6-hour fast prior to endoscopy. A local pharyngeal anesthetic was administered ( $2 \%$ xylocaine spray) prior to the procedure. The patient was placed in the left lateral decubitus position and a mouth guard inserted. The endoscopist passed the extreme distal end of the endoscope through the mouth guard, observing through the eyepiece or monitor its passage over the tongue, then the epiglottis and vocal cords, the interior of the esophagus, continuing in this manner until reaching the second segment of the duodenum. On reaching this point, the endoscope was slowly retracted, the endoscopist examining the entire trajectory through which the instrument had advanced.[11]

Helicobacter pylori infection To assess prevalence of $H$. pylori infection (overall and specific by age and disease), a mucus specimen was taken from the gastric antrum at the incisura angularis of every participant, regardless of endoscopic indication or diagnosis. $H$. pylori was identified with a urease test using Urepyl (a reagent produced and standardized at the research laboratory of Cuba's IGE and distributed to all endoscopy services in the country).[12,13]

Quality Endoscopists' competence was evaluated with a validated questionnaire covering technical quality of the endoscopy and diagnostic accuracy.[14] Assessment was by an external committee of evaluators assembled for this purpose, comprising 10 professors of gastroenterology with recognized expertise, who evaluated in situ at all of the polyclinics a simple random sample of 280 patients, or $8 \%$ of study participants. A five-point scale-very good, good, fair, poor, very poor-was used to classify endoscopists' work on six dimensions considered fundamental in upper GI endoscopy: (1) appropriateness of the indication; (2) time between patient arrival and procedure; (3) procedure explanation given the patient by the attending physician; (4) technical quality of the endoscopy; (5) quality of diagnostic report; and (6) equipment cleaning and disinfection.

Information gathering General information about the participants, their clinical and epidemiologic data, information on expo-
Table 1: Study variables

Variable

Description

$<20$

20-29

$30-39$

Age group (years) $\quad 40-49$

$50-59$

$60-69$

$70-79$

$\geq 80$

Sex Male, female

Skin color

Black, mestizo, white

$\begin{array}{ll}\text { Single } & \text { Warital status } \\ \text { With a partner } \\ \text { Married } \\ \text { Divorced } \\ \text { Widowed }\end{array}$

Illiterate

Education Primary school

completed Middle school

Secondary (high) school

University

\begin{tabular}{|c|c|}
\hline Occupation & $\begin{array}{l}\text { Professional } \\
\text { Technical } \\
\text { Laborer } \\
\text { Student } \\
\text { Homemaker } \\
\text { Retiree } \\
\text { Military } \\
\text { Other }\end{array}$ \\
\hline $\begin{array}{l}\text { Obesity } \\
\left(\text { BMI in } \mathrm{kg} / \mathrm{m}^{2}\right)\end{array}$ & $\begin{array}{ll}\text { Overweight or obese } & \geq 25 \\
\text { Not obese } & <25\end{array}$ \\
\hline $\begin{array}{l}\text { Family history of } \\
\text { disease of segment } \\
\text { studied }\end{array}$ & $\begin{array}{l}\text { Diagnosis in a first-degree relative of: } \\
\text { Gastrointestinal cancer } \\
\text { Ulcer } \\
\text { Gastritis } \\
\text { Hiatal hernia }\end{array}$ \\
\hline Risk factors & $\begin{array}{l}\text { Self-reported: } \\
\text { Current smoking } \\
\text { Current alcohol use } \\
\text { Coffee }>2 \text { cups a day } \\
\text { ASA, current use } \\
\text { Other NSAIDs, current use } \\
\text { Steroids, current use } \\
\text { H. pylori }\end{array}$ \\
\hline Psychosocial factors & $\begin{array}{l}\text { Self-report in the previous six months of: } \\
\text { Death of a close relative } \\
\text { Problems with spouse or partner } \\
\text { Legal charges } \\
\text { Job change } \\
\text { Loneliness }\end{array}$ \\
\hline
\end{tabular}

ASA: Acetylsalicylic acid

BMI: Body Mass Index

NSAIDs: Nonsteroidal anti-inflammatory drugs

sure to risk factors and endoscopy results were recorded on standardized forms, which were sent to IGE for processing and analysis once completed in the polyclinics.

Data analysis Information from the forms was entered in a database using Epilnfo 6.04 and statistical analysis performed using the same software and its EPI 2000 version for Windows. Prevalences of dependent and independent variables in the study population were calculated as percentages. Analysis of potential sociodemographic, hereditary and psychosocial predictors, as 
well as others such as $H$. pylori infection and use of medications, and their association with positive endoscopic diagnoses, was performed using univariate statistical techniques (chi-square test and Fisher's exact tests); and resulting independent variables associated $(p<0.05)$ were included in a model for multivariate analysis (unconditional logistic regression). The measure of association strength was the odds ratio (OR), with significance level set at $p<0.05$ (or $95 \%$ confidence interval excluding 1.0).

Ethical considerations All patients provided written informed consent for participation. The study was approved by the IGE Research Ethics Committee.

\section{RESULTS}

The external evaluation committee assessed as "very good" or "good" the quality of $99.3 \%$ of endoscopies and $97.9 \%$ of reports.

The study sample used was $115 \%$ of the minimum necessary for estimates of the desired precision and confidence, representing approximately $50 \%$ of all people undergoing upper $\mathrm{Gl}$ endoscopy for the first time in 2007 in Havana polyclinics. Seventeen polyclinics surpassed their sample goal and the remaining five achieved a sample greater than $80 \%$ of target.

Of the 3556 participants, $63 \%$ (2239) were women and $37 \%$ (1317) men; $72 \%$ (2560) were of working age (18-59 years) (Table 2). Of the total, $55.6 \%$ (1976) had completed secondary school; $59 \%$ (2098) were married or cohabiting; $55.5 \%$ (1974) were white; and $24.4 \%$ (867) were laborers.

In the study population, $32.8 \%$ were smokers; $28.5 \%$ drank alcohol; $58.7 \%$ drank more than two cups of coffee a day; $2.6 \%$ took aspirin, $10 \%$ other nonsteroid anti-inflammatories (NSAIDs), and $1.2 \%$ steroids. Some $30.1 \%$ reported having experienced gastritis at some point in their life, $18.3 \%$ peptic ulcers, and $3.1 \%$ esophagitis; while $24.3 \%$ had a first-degree family history of gastritis, $22.4 \%$ peptic ulcers, $10.5 \%$ hiatal hernias and $7.9 \%$ GI cancers.

Slightly over half $(57.1 \%)$ complained of being "stressed," and $21.8 \%$ said that they had experienced important life changes in the previous six months. Specifically, $19.9 \%$ said they felt lonely; $13.9 \%$ had recently lost a close relative; $12.2 \%$ were having prob-

Table 2: Age and sex distribution of patients receiving endoscopy in primary care in Havana polyclinics, May-November, 2007 ( $n=3556)$

\begin{tabular}{|c|c|c|c|c|c|c|}
\hline \multirow{2}{*}{ Age group (years) } & \multicolumn{2}{|c|}{ Women } & \multicolumn{2}{|c|}{ Men } & \multicolumn{2}{|c|}{ Total } \\
\hline & No. & $\%$ & No. & $\%$ & No. & $\%$ \\
\hline$<20$ & 59 & 2.6 & 28 & 2.1 & 87 & 2.4 \\
\hline $20-29$ & 217 & 9.7 & 146 & 11.1 & 363 & 10.2 \\
\hline 30-39 & 362 & 16.2 & 268 & 20.3 & 630 & 17.7 \\
\hline $40-49$ & 555 & 24.8 & 297 & 22.6 & 852 & 24.0 \\
\hline $50-59$ & 455 & 20.3 & 239 & 18.1 & 694 & 19.5 \\
\hline $60-69$ & 366 & 16.3 & 195 & 14.8 & 561 & 15.8 \\
\hline 70-79 & 168 & 7.5 & 110 & 8.4 & 278 & 7.8 \\
\hline$\geq 80$ & 33 & 1.5 & 22 & 1.7 & 55 & 1.6 \\
\hline Age unknown & 24 & 1.1 & 12 & 0.9 & 36 & 1.0 \\
\hline TOTAL & 2239 & 100.0 & 1317 & 100.0 & 3556 & 100.0 \\
\hline
\end{tabular}

Women $63 \%$ of total; Men $37 \%$; Ratio $\mathrm{F} / \mathrm{M}=1.7$

Average age: $W 48.3$ years; $M 47.4$ years lems with spouses or partners; $11.1 \%$ had recently switched jobs; and $1 \%$ had recently faced legal charges.

Most commonly reported symptoms were epigastric pain, $71.4 \%$ (2540); acid indigestion, 56.8\% (2019); dyspepsia-assorted symptoms, problems, or discomfort related to the upper $\mathrm{GI}$ tract-43.7\% (1555); heartburn, 24.2\% (859); abdominal pain, $17.1 \%$ (608); and reflux, $14.1 \%$ (502). A triad of symptoms consisting of epigastralgia, acid indigestion and dyspepsia (nonspecific symptoms or a sensation of discomfort) was observed quite frequently.

The urease test for detecting $H$. pylori infection was performed on specimens from all patients; analysis was based on 3444 satisfactory specimens for which there were complete data, $96.9 \%$ of total; of these, 2011 (58.4\%) were positive. H. pylori positivity was significantly more frequent $(p<0.001)$ in men $(62 \%)$ than in women $(56.2 \%)$, and prevalence increased in the fourth to sixth decades of life, declining slightly in those aged $\geq 70$ years (Figure 1). Prevalences of $H$. pylori infection by diagnosis were: duodenal ulcer, $77.7 \%$; gastric ulcer, $69.4 \%$; duodenitis, $63 \%$; gastritis, $60.1 \%$; and esophagitis, $55.2 \%$.

Figure 1: Endoscopic prevalence of $H$. pylori by age group in Havana polyclinics, May-November, 2007 ( $n=3444)$

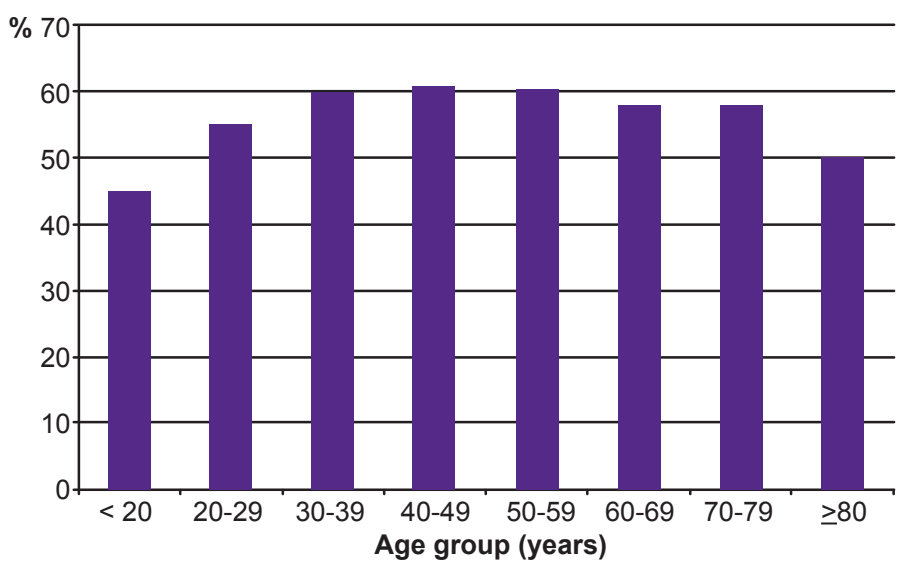

Frequency and distribution of upper GI diseases and associated risk factors The most frequent diagnoses were: gastritis $(91.6 \%)$, duodenitis $(57.8 \%)$ and hiatal hernia (46.5\%) (Table 3). In general, duodenitis, duodenal ulcer and gastric ulcer were significantly more frequent in men $(p<0.001)$, while esophagitis $(p=0.03)$ and hiatal hernia $(p=0.02)$ were more frequent in women. Prevalence of gastritis was similar in both sexes. Table 3 displays the total number of diagnoses for each condition in men and women, average age, the population subgroups with higher prevalence and the frequency of associations among the different diagnoses.

Esophagitis. Some $73.3 \%$ of the cases were considered reflux esophagitis; $1.9 \%$ were classified as monilial and in $24.8 \%$, no probable etiology was specified. None of the variables included in the model behaved as a predictor for esophagitis, and only coffee drinking turned out to be a protective factor (Table 4).

Hiatal hernia. Family history was reported by $13.9 \%$. Risk of hiatal hernia almost doubled in the presence of family history (OR 1.96, $\mathrm{Cl}$ 1.56-2.45). This effect disappeared in multivariate analysis. 
Table 3: Common upper GI tract conditions in patients receiving endoscopy in Havana polyclinics, MayNovember, $2007(n=3556)$

\begin{tabular}{|c|c|c|c|c|c|c|c|c|c|c|c|}
\hline \multirow{3}{*}{ Diagnosis } & \multirow{3}{*}{ No. } & \multirow{2}{*}{\multicolumn{3}{|c|}{$\begin{array}{c}\text { Prevalence } \\
(\%)\end{array}$}} & \multicolumn{3}{|c|}{ Age (years) } & \multirow{3}{*}{\multicolumn{2}{|c|}{$\begin{array}{l}\text { Subgroups with highest } \\
\text { prevalence (\%) }\end{array}$}} & \multirow{3}{*}{\multicolumn{2}{|c|}{$\begin{array}{c}\text { GI comorbidities } \\
(\%)\end{array}$}} \\
\hline & & & & & \multirow{2}{*}{ Mean } & \multicolumn{2}{|c|}{$\begin{array}{l}\text { Extreme } \\
\text { values }\end{array}$} & & & & \\
\hline & & Total & M & $F$ & & Min & Max & & & & \\
\hline Esophagitis & 895 & 25.2 & 23.1 & 26.4 & 43.7 & 18 & 89 & $\begin{array}{l}<20 \text { years } \\
\text { Students }^{\mathrm{b} 1} \\
\text { Single }^{\mathrm{b} 2} \\
\text { University educated }^{\mathrm{b}} \\
\text { Mestizo } \\
\text { Women }\end{array}$ & $\begin{array}{r}50.0 \\
42.1 \\
28.6 \\
27.4 \\
26.5 \\
23.1\end{array}$ & $\begin{array}{l}\text { Gastritis } \\
\text { Duodenitis } \\
\text { Duodenal ulcer } \\
\text { Gastric ulcer }\end{array}$ & $\begin{array}{r}92.5 \\
60.4 \\
12.5 \\
4.6\end{array}$ \\
\hline $\begin{array}{l}\text { Hiatal } \\
\text { hernia }\end{array}$ & 1653 & 46.5 & 44.0 & 47.3 & 50.0 & 18 & 89 & $\begin{array}{l}\text { Coffee }^{\mathrm{b4}} \\
\text { Women }^{\mathrm{b5}} \\
\text { Family history }\end{array}$ & $\begin{array}{l}63.2 \\
47.3 \\
13.9\end{array}$ & $\begin{array}{l}\text { Gastritis } \\
\text { Duodenitis } \\
\text { Esophagitis } \\
\text { Duodenal ulcer } \\
\text { Gastric ulcer }\end{array}$ & $\begin{array}{r}93.0 \\
61.0 \\
27.5 \\
15.8 \\
5.9\end{array}$ \\
\hline Gastritis & 3256 & 91.6 & 92.5 & 91.0 & 44.6 & 18 & 96 & $\begin{array}{l}\text { Widow(er)s } \\
\text { Retirees } \\
\text { Men } \\
\text { White skin } \\
\text { Primary school } \\
\text { Coffee drinkers }\end{array}$ & $\begin{array}{l}96.1 \\
93.8 \\
92.5 \\
92.2 \\
92.0 \\
59.3\end{array}$ & $\begin{array}{l}\text { Duodenitis } \\
\text { Esophagitis } \\
\text { Duodenal ulcer } \\
\text { Gastric ulcer }\end{array}$ & $\begin{array}{r}59.0 \\
25.4 \\
15.5 \\
5.7\end{array}$ \\
\hline $\begin{array}{l}\text { Gastric } \\
\text { ulcer }\end{array}$ & 220 & 6.2 & 7.7 & 5.3 & 54.4 & 19 & 87 & $\begin{array}{l}\text { Coffee drinkers } \\
\text { Stress } \\
\text { Smokers }{ }^{\mathrm{b} 7} \\
\text { Alcohol } \\
\text { Family history } \\
\geq 70 \text { years } \\
\text { NSAIDS } \\
\text { Retirees } \\
\text { Men }^{\mathrm{b} 8}\end{array}$ & $\begin{array}{r}67.7 \\
53.2 \\
41.8 \\
30.9 \\
22.7 \\
12.5 \\
10.9 \\
10.9 \\
7.7\end{array}$ & $\begin{array}{l}\text { Gastritis } \\
\text { Duodenitis } \\
\text { Hiatal hernia } \\
\text { Esophagitis } \\
\text { Duodenal ulcer }\end{array}$ & $\begin{array}{l}84.1 \\
55.0 \\
44.5 \\
18.6 \\
10.0\end{array}$ \\
\hline $\begin{array}{l}\text { Duodenal } \\
\text { ulcer }\end{array}$ & 562 & 15.8 & 23.4 & 11.3 & 50.0 & 18 & 85 & $\begin{array}{l}\text { Coffee drinkers } \\
\text { Smokers }^{\mathrm{b} 7} \\
\text { Men }^{\mathrm{b} 8} \\
\text { Alcohol }^{\mathrm{b} 9} \\
\text { Stress } \\
\text { Family history }^{\mathrm{b} 6} \\
\text { Military }^{\mathrm{b} 1}\end{array}$ & $\begin{array}{l}59.3 \\
47.9 \\
23.4 \\
35.1 \\
56.5 \\
29.5 \\
33.3\end{array}$ & $\begin{array}{l}\text { Gastritis } \\
\text { Duodenitis } \\
\text { Hiatal hernia } \\
\text { Esophagitis } \\
\text { Gastric ulcer }\end{array}$ & $\begin{array}{r}90.0 \\
77.4 \\
46.4 \\
20.0 \\
3.9\end{array}$ \\
\hline Duodenitis & 2056 & 57.8 & 63.5 & 54.4 & 49.0 & 18 & 96 & $\begin{array}{l}\text { Military } \\
\text { Primary schoolb2 }^{\text {bimen }} \text { Men }^{\mathrm{b}} \\
\text { Coffee drinkers } \\
\text { Married } \\
\text { Smokers } \\
\text { 70-79 years }\end{array}$ & $\begin{array}{l}69.4 \\
66.5 \\
63.5 \\
59.1 \\
58.3 \\
35.6 \\
20.0\end{array}$ & $\begin{array}{l}\text { Gastritis } \\
\text { Hiatal hernia } \\
\text { Esophagitis } \\
\text { Duodenal ulcer } \\
\text { Gastric ulcer }\end{array}$ & $\begin{array}{r}93.8 \\
49.1 \\
26.3 \\
21.2 \\
5.9\end{array}$ \\
\hline
\end{tabular}

a Excluding malignant-appearing lesions; N Total= 3556; Women 2239; Men 1317

${ }^{b}$ Prevalence in specific subgroup differs significantly from the rest

b1 Occupation: Students vs. other occupations for esophagitis $(p<0.001)$; Military vs. other for duodenal ulcer $(p<0.001)$

b2 Marital status: Single and divorced people vs. married people and people living with a partner for esophagitis $(p=0.017)$

b3 Education completed: People with a university education vs. people with lower levels of education for esophagitis $(p<0.001)$ and people with primary level for duodenitis $(p<0.001)$

${ }^{b 4}$ Coffee: as a protective factor for hiatal hernia $(p<0.001)$; gastritis $(p=0.023)$

${ }^{b 5}$ Sex: Women vs. men for esophagitis $(p=0.03)$ and hiatal hernia $(p=0.017)$

${ }^{\mathrm{b} 6}$ Family history: Duodenal ulcer and hiatal hernia $(p<0.001)$

b7 Smoking: Gastric ulcer, duodenal ulcer and duodenitis $(p<0.001)$

${ }^{b 8}$ Sex: Men vs. women for duodenal ulcer, gastric ulcer and duodenitis $(p<0.001)$

${ }^{b 9}$ Alcohol use: Duodenal ulcer $(p=0.007)$

Overweight-obesity (BMI > 24.99) did not behave as a predictor of hiatal hernia ( $p>0.05$ ); univariate analysis found discrete positive associations with $H$. pylori infection (OR 1.24, Cl 1.08-1.42) and coffee drinking (OR 1.42, Cl 1.24-1.63). Multivariate analysis reaffirmed $H$. pylori infection as an independent predictor, as well as age $\geq 40$ years, female and white skin color (Table 4 ).

Gastritis. Some $63.8 \%$ of the gastritis cases were classified as erythematous, $18.2 \%$ as erosive and $14.7 \%$ as reflux; type was not reported in the remaining $3.3 \%$. Regarding location, $55.5 \%$ of diagnoses were limited exclusively to the gastric antrum, $5.4 \%$ to the corpus and $33.4 \%$ affected the entire stomach; for $5.7 \%$ there was no indication.

In those with gastritis, $59.3 \%$ were coffee drinkers and $33.1 \%$ smokers; $28.9 \%$ drank alcohol; $10.3 \%$ took NSAIDs with certain regularity, $2.7 \%$, aspirin and $1.3 \%$, steroids; and $60.1 \%$ of all tests were positive for $H$. pylori.

Univariate analysis showed that H. pylori infection was a significant risk factor for gastritis (OR 2.28, Cl1.77-2.94) and there was a slight association with coffee drinking (OR 1.33, Cl 1.04-1.69). Using multivariate analysis to study all these independent variables yielded similar results for $H$. pylori, and over age 40 appeared as another associated risk factor; however, coffee drinking disappeared as a potential predictor of gastritis (Table 4).

Duodenitis. Exposure to potential predictive or risk factors was as follows: $59.1 \%$ drank coffee; $35.6 \%$ smoked, and $28.7 \%$ drank alcohol; $10 \%$ regularly took NSAIDs, $2.9 \%$ aspirin and $1.1 \%$ steroids; and $63.1 \%$ tested positive for $H$. pylori.

Univariate analysis showed that H. pylori infection (OR 1.58, Cl 1.38-1.82) and smoking (OR 1.46, $\mathrm{Cl} 1.17-1.56)$ behaved as risk factors, and this was confirmed in multivariate analysis. Moreover, being male and aged $\geq 60$ years also had an effect. Alcohol consumption behaved as a discrete protective factor (Table 4).
Duodenal ulcer. The triad of symptoms most commonly associated with diagnosis of duodenal ulcer was epigastric pain $(77.9 \%)$, acid indigestion (64.4\%) and dyspepsia (40.4\%); however, other symptoms were also present to a lesser extent, among them heartburn (26.7\%), nonspecific abdominal pain (21.5\%) and reflux (13.2\%).

This diagnosis was accompanied by gastritis in $90 \%$ of cases, duodenitis in $77.4 \%$, hiatal hernia in $46.4 \%$ and esophagitis in $20 \%$ (Table 3 ). 
Table 4: Factors associated with upper GI tract conditions in patients receiving endoscopy in Havana polyclinics, MayNovember, 2007 (multivariate analysis, unconditional logistic regression)

\begin{tabular}{|c|c|c|c|c|}
\hline Condition & $\begin{array}{c}\text { Factor } \\
\text { (comparison) }\end{array}$ & OR & Cl $95 \%$ & p Value \\
\hline Esophagitis & Coffee consumption & 0.59 & $0.35-0.90$ & 0.020 \\
\hline Hiatal hernia & $\begin{array}{l}\text { H. pylori }(+/-) \\
\text { Skin color }(\mathrm{M}+\mathrm{B} / \mathrm{W}) \\
\text { Age } \geq 40 \text { years }(\mathrm{Y} / \mathrm{N}) \\
\text { Sex }(\mathrm{M} / \mathrm{F}) \\
\text { Coffee }(\mathrm{Y} / \mathrm{N})\end{array}$ & $\begin{array}{l}1.24 \\
0.86 \\
1.57 \\
0.83 \\
1.29\end{array}$ & $\begin{array}{l}1.08-1.43 \\
0.75-0.99 \\
1.33-1.84 \\
0.71-0.97 \\
1.11-1.51\end{array}$ & $\begin{array}{r}0.002 \\
0.040 \\
<0.001 \\
0.020 \\
0.001\end{array}$ \\
\hline Gastritis & $\begin{array}{l}\text { Age } \geq 40 \text { years }(\mathrm{Y} / \mathrm{N}) \\
\text { H. pylori }(+/-)\end{array}$ & $\begin{array}{l}1.51 \\
2.29\end{array}$ & $\begin{array}{l}1.14-2.00 \\
1.79-2.95\end{array}$ & $\begin{array}{r}0.004 \\
<0.001\end{array}$ \\
\hline Gastric ulcer & $\begin{array}{l}\text { Age } \geq 60 \text { years } \\
\text { Male sex } \\
\text { Smoking } \\
\text { H. pylori (+/-) }\end{array}$ & $\begin{array}{l}1.78 \\
1.42 \\
1.39 \\
1.58\end{array}$ & $\begin{array}{l}1.28-2.47 \\
1.04-1.95 \\
1.01-1.90 \\
1.17-2.15\end{array}$ & $\begin{array}{r}<0.001 \\
0.030 \\
0.042 \\
0.003\end{array}$ \\
\hline Duodenitis & $\begin{array}{l}\text { Alcohol }(\mathrm{Y} / \mathrm{N}) \\
\text { Age } \geq 60 \text { years }(\mathrm{Y} / \mathrm{N}) \\
\text { Sex }(\mathrm{M} / \mathrm{F}) \\
\text { Smoking }(\mathrm{Y} / \mathrm{N}) \\
\text { H. pylori }(+/-)\end{array}$ & $\begin{array}{l}0.80 \\
1.28 \\
1.46 \\
1.38 \\
1.58\end{array}$ & $\begin{array}{l}0.67-0.96 \\
1.06-1.54 \\
1.24-1.70 \\
1.17-1.62 \\
1.38-1.82\end{array}$ & $\begin{array}{r}0.014 \\
0.009 \\
<0.001 \\
<0.001 \\
<0.001\end{array}$ \\
\hline $\begin{array}{l}\text { Duodenal } \\
\text { ulcer }\end{array}$ & $\begin{array}{l}\text { Coffee }(\mathrm{Y} / \mathrm{N}) \\
\text { Skin color }(\mathrm{M}+\mathrm{B} / \mathrm{W}) \\
\text { Age } \geq 40 \text { years }(\mathrm{Y} / \mathrm{N}) \\
\text { Sex }(\mathrm{M} / \mathrm{F}) \\
\text { Smoking }(\mathrm{Y} / \mathrm{N}) \\
\text { H. pylori }(+/-)\end{array}$ & $\begin{array}{l}0.78 \\
1.22 \\
1.46 \\
2.30 \\
2.08 \\
2.70\end{array}$ & $\begin{array}{l}0.63-0.97 \\
1.01-1.48 \\
1.16-1.85 \\
1.87-2.83 \\
1.68-2.58 \\
2.17-3.36\end{array}$ & $\begin{array}{r}0.026 \\
0.043 \\
0.002 \\
<0.001 \\
<0.001 \\
<0.001\end{array}$ \\
\hline
\end{tabular}

M: mestizo B: black W: white

One hundred percent of ulcers were located in the first part of the duodenum (bulb). There was a single lesion in $84.5 \%$ of patients, two lesions in $10 \%$ and multiple lesions in $5.5 \%$. Some $3.9 \%$ (22 persons) also had gastric ulcer. Round shapes predominated $(59.2 \%)$, followed by linear shapes $(21.3 \%)$, "salami ulcers" (13.2\%), star shapes (4.8\%) and less often, "kissing ulcers" (1.5\%). Some $70 \%$ were superficial and $16.2 \%$ deep (this information was not provided in $13.8 \%$ of patients). Based on their progression, the vast majority $(72.2 \%)$ were considered active ulcers.

Potential risk factors considered predictive of duodenal ulcer were as follows: $59.3 \%$ of patients were coffee drinkers and $47.9 \%$ smokers; $35.1 \%$ drank alcohol; $8.7 \%$ regularly took NSAIDs; $3 \%$ took aspirin and $1.1 \%$ steroids. Among the psychosocial factors involved in the etiology of peptic ulcers (especially ulcers in the duodenum), most acting as co-factors or triggers of their clinical manifestation, it was found that of the 562 patients with duodenal ulcer, $56.5 \%$ indicated that they were under "considerable" stress, $22.4 \%$ indicated that they had experienced major life changes in the six months prior to the endoscopy, $15.1 \%$ had recently lost a close relative, $13.4 \%$ were having problems with their spouse or partner and $1.3 \%$ said they had recently faced legal charges. Despite the relatively high frequency of some of these variables, statistical analysis did not show a significant association between diagnosis of duodenal ulcer and any of them.

Family history of peptic ulcer was present in $29.5 \%$ of patients with duodenal ulcer and behaved as a potential predictor (OR 1.57, Cl 1.28-1.93), but when persons with duodenal ulcers positive for $H$. pylori were disaggregated from those negative for this agent, fam- ily history of peptic ulcer remained predictive for $\mathrm{H}$. pylori-positive (OR 1.52, Cl 1.19-1.95), but not $H$. pylori-negative cases (OR 1.51, Cl 0.97-2.33).

In univariate analysis, the strongest associations with duodenal ulcer were for $\mathrm{H}$. pylori (OR 2.76, Cl 2.23-3.44) and smoking (OR $2.14, \mathrm{Cl} 1.77-2.58)$ and, to a lesser extent, alcohol consumption (OR 1.44, $\mathrm{Cl} 1.18-1.75)$. Multivariate analysis using a model including these variables reaffirmed $H$. pylori infection as the most important predictor of duodenal ulcer (OR 2.70, Cl 2.17-3.36). Alcohol no longer behaved as a risk factor, and coffee appeared to have a slight protective effect (Table 4).

Gastric ulcer. Symptoms most often mentioned were epigastric pain $(81.8 \%)$, acid indigestion $(57.3 \%)$ and dyspepsia $(42.3 \%)$. Fifty percent of patients reported epigastric pain and acid indigestion combined, and the epigastric pain-acid indigestion-dyspepsia symptom triad was present in $25 \%$ of patients.

Antral location (81.4\%), round shape (56.6\%) and a single lesion were the descriptions most often reported. Some $69.4 \%$ were superficial, $56.1 \%$ were $<1 \mathrm{~cm}$ in any dimension, $76.4 \%$ were classified as "active ulcers," and only four cases (1.8\%) were described as "appearing malignant."

Exposure to potential factors predictive of gastric ulcer behaved as follows: $67.7 \%$ were coffee drinkers; $41.8 \%$ were smokers; $30.9 \%$ drank alcohol; $10.9 \%$ regularly took NSAIDs, 3.6\% aspirin, and $0.5 \%$ steroids; and $69.4 \%$ were positive for $H$. pylori.

Of the 220 with gastric ulcer, $53.2 \%$ stated that they were under stress; $17.9 \%$ said they had experienced major life changes in the six months prior to endoscopy; $14.2 \%$ had recently lost a close relative; $11.5 \%$ were having problems with their spouse or partner and $1.4 \%$ indicated they had recently faced legal charges. Moreover, one in five patients with gastric ulcers (19.3\%) said they felt lonely all the time and $8.7 \%$ indicated they no longer had anyone to provide emotional support in highly stressful situations. None of these variables showed a significant association with the diagnosis of gastric ulcer.

A history of peptic ulcer in a first-degree relative was present in $22.7 \%$ of persons with gastric ulcer, but estimating an increased risk for the subgroup of persons with a family history was not possible (OR 1.02, Cl 0.73-1.43).

Through univariate analysis the following were identified as independent variables for gastric ulcer: $H$. pylori infection (OR 1.66, Cl 1.22-2.28), smoking (OR 1.51, Cl 1.13-2.01) and coffee drinking (OR 1.51, CI 1.12-2.05), while multivariate analysis showed $H$. pylori infection and smoking retained their effect, and age and male sex became important (Table 4).

Cancer and malignant-appearing lesions in the upper GI tract. Since positive diagnosis of malignant lesions is histological, this section includes only endoscopic suspicions of cancer and malignant-appearing lesions.

A total of three patients $(0.1 \%)$ received a presumptive diagnosis of esophageal cancer, eight $(0.2 \%)$ of stomach cancer and four $(0.1 \%)$ of malignant-appearing gastric ulcers-in all, 15 persons with an endoscopic diagnosis of "malignant-appearing lesion," for 
a prevalence of $0.4 \%$; that is, one presumptively malignant lesion was found per 237 endoscopies.

The three cases identified as presumptive esophageal cancer were men aged 41,58, and 80; among the presumptive cases of stomach cancer, four were men and four women with ages ranging from 42 to 75 . Of the latter, two were diagnosed in the early stage and six in advanced stages. The risk for $\mathrm{Gl}$ cancer was estimated as three times higher for men than for women (OR 3.42, Cl 1.06-12.8).

\section{DISCUSSION}

The decision of the Ministry of Public Health to provide GI endoscopy services in the primary health care network in Cuba made this study possible, and with it, acquisition of information on the frequency of and risk factors associated with the most common diseases of the digestive tract in the health services level most accessible to patients. This resulted in indicators that were closer to their real distribution in the population, in comparison with those obtained until now in hospitals, where a more narrowly-defined subset of patients is seen, often those more seriously ill.

In this regard, our literature review yielded only a few studies from the United States and the United Kingdom on GI endoscopies performed by physicians at the primary care level and on nurses working at that level; however, none of them described results on the frequency and distribution of the principal diseases of the upper GI tract.[7-9] The unique characteristics of Cuba's primary health care subsystem made it possible to obtain this information more readily and precisely[15] and to provide rates for a specific geographically-defined population.

Studies in the United States[7,16] conclude that it is probable that endoscopies performed at the primary care level do not always comply with the national technical recommendations; thus, the number of inappropriate indications tends to be higher in comparison with that of specialized health services. These studies conclude that allowing primary care physicians to perform endoscopies should be reevaluated. In contrast, some studies in the United Kingdom conclude that there are no significant differences in results of upper $\mathrm{Gl}$ endoscopies done at the primary care level, even when performed by nurses instead of physicians. $[8,17]$

In Cuba, PHC endoscopy services are coordinated by and closely connected with hospital gastroenterology services where upper $\mathrm{GI}$ endoscopy is not only diagnostic, but prognostic and therapeutic. Thus, specialist competition with PHC services is not a factor in patient care, since the two are complementary.[18]

The relative frequencies of diagnosis of the principal diseases of the upper Gl tract obtained in primary care were the ones expected when compared with a series of consecutive endoscopies performed at IGE in 2007. The frequency of diagnosis in a series of 1575 patients seen consecutively in IGE between September 2007 and May 2008 showed that gastritis was also the most frequent $(82 \%)$, followed by hiatal hernia $(31.6 \%)$, duodenitis $(31.1 \%)$, duodenal ulcer $(9.7 \%)$, esophagitis $(9.4 \%)$, gastric ulcer (3.4\%) and malignant lesions (0.95\%).[18] In general, there is a higher prevalence of inflammation and benign ulcers in patients seen in primary care, while malignant-appearing lesions are seen almost twice as often in IGE, consistent with the types of patients that should be seen in primary care and tertiary care levels.

The prevalence of $H$. pylori infection varies with population socioeconomic status, with lower-income countries exhibiting higher rates than higher-income countries.[1] Infection is very high in Africa, Asia, and many parts of Central and South America $(\geq 90 \%)$, while it is relatively low in northern and eastern Europe, North America, and Australia ( $<50 \%$ ). [1] This infection is contracted early in life; over $50 \%$ of children worldwide are infected by the age of 10,[19-22] and, once again, the most important risk factor for contracting $H$. pylori infection appears to be the low socioeconomic status of the child's family.[23]

Studies by Gutiérrez et al. on $H$. pylori prevalence in Cuba in the normal population and dyspeptic patients in Havana, using a set of serologic diagnostic reagents for the detection of $H$. pylori lgG antibodies, show prevalences of infection ranging from $75 \%$ to $100 \%$, although data were obtained from relatively small population samples. The prevalence values for $H$. pylori infection found in each of the diseases in this study are within usual range observed with the urease test; values may vary with the location of the mucosa, the number of specimens taken and the waiting time for observing the change in color.[1,2]

Our study presents the first epidemiologic data on diseases of the upper GI tract for a geographically-defined population in Cuba. Gastritis, the diagnosis most frequently encountered in PHC in Havana, is also the most common diagnosis in the majority of upper GI endoscopy series published in the literature. In a study that included patients from four countries on three continents (Japan, China, Tanzania, and the Dominican Republic), Aoki et al. reported gastritis prevalence rates ranging from $23.5 \%$ to $96.5 \%$.[22]

The prevalence of esophagitis found in our study is quite similar to that reported by Du in China,[23] who found a rate of $20.8 \%$ among 2231 patients. This in turn was higher than the $15.8 \%$ also reported in China by Tseng[24] and the $12 \%$ reported by Kim in a major study conducted in South Korea with 25,536 subjects[25] and by Chen in Taiwan (12\%).[26]

A Swedish endoscopy study of peptic ulcer[27] in a random sample of 1001 persons from two communities found a relatively low prevalence (4.1\%). However, other non-population-level studies involving series of patients spontaneously presenting in hospitals found higher prevalences: 7\% in Finland,[28] 8.3\% in Peru,[4] $11.5 \%$ in Kuwait,[29] $15 \%$ in the United States (Alaska),[30] $17.2 \%$ in China[31] and $31.8 \%$ in Poland.[32] The prevalence found in Havana is within the range of reported values.

Risk factors associated with diseases of the upper GI tract in this study generally coincide with those reported by other authors. A selection of published articles on studies in Europe, Asia, and the Americas shows that $H$. pylori infection is the main predictor of peptic ulcer disease,[4,25,31-34] followed by smoking,[31,32,35-37] although some authors do not consider the latter an independent predictor but rather a synergistic co-factor with $\mathrm{H}$. pylori infection. $[33,35]$ Other risk factors associated with peptic ulcer found in the literature are: male sex,[23,36] advanced age,[23,28] prior history of ulcer,[21] use of aspirin or other NSAIDs[28,32,36,37] and being divorced.[23] Alcohol consumption is reported as a risk factor in some studies[23] and as a protective factor in others.[36] Moderate 
physical exercise, a variable not included in our study, has been cited as an independent protective factor against peptic ulcer.[31]

Drugs such as aspirin and other NSAIDs are considered predictors of significant risk for gastric ulcer,[31,32] but this study was not able to show that association.

Without a doubt, $H$. pylori infection is the main predictor of gastritis, $[21,34]$ just as hiatal hernia, male sex, smoking, drinking alcohol, and overweight-obesity are for esophagitis.[26]

Limitations of this study include use of a diagnostic test for $\mathrm{H}$. pylo$r i$ that, while highly sensitive and specific with positive predictive values of $>90 \%$ when compared with histological diagnosis, has not been validated against another similar, commercially available test; thus, the existence of a certain degree of underreporting of $H$. pylori prevalence cannot be ruled out. Another limitation is that pathology confirmation was not obtained for some diagnoses, especially those related to malignant-appearing lesions. The failure to show the use of aspirin or other NSAIDs as an important factor for development of gastric ulcers may be associated with the low sensitivity of the questionnaire employed in terms of how questions about their use were formulated, and perhaps greater use of buffered varieties of these types of drugs in our environment in recent years.

\section{CONCLUSIONS}

This study's greatest merit is that it contributes information on the frequency of a group of diseases whose prevalence is virtually unknown in Cuba and most countries. Its implementation in a sample population residing in a well-defined territory with good and similar guarantees of access to diagnostic services and prompt data acquisition offer greater guarantees of accuracy and precision of epidemiologic results, compared to traditional studies published in the international literature that focus on the population seeking care at hospitals.

For the first time in Cuba, important population-based data were obtained on frequency of the most common diseases of the upper GI tract and their main risk factors. This information, together with a network of patient-accessible diagnostic endoscopy services at the primary care level, lays the foundation for future studies and facilitates objective recommendations on community-based interventions for prevention and control of these diseases.

\section{ACKNOWLEDGMENTS}

The authors are grateful to the following colleagues who collaborated in study design, organization or data management:

Drs Héctor Hernández Garcés, Pedro Gil González, William Haedo Quiñones, Carlos Fábregas Rodríguez, Rolando Martínez López, Mirta Infante Velásquez, Miguel González-Carvajal Pascual, Orlando Nodarse Pérez, Juan Antonio Mas Páez, Hermidio Hernández Mulet and Amada Palomino Besada; and technician Fabiola Medina Colina.

We also thank the primary care personnel who interviewed patients and performed endoscopies:

Drs Nuvia Figueredo Zayas, Armando Orellana Molina, Eduardo Morandeira Abreu, Libia Isela González Hernández, Juan Castellanos Safonts, Elsa Tamara Chávez Rivero, Gustavo Veitía, Yanet Valdés Viera Corrales, Ileana Pacho Saavedra, Jaqueline Vega Bello, Humberto Soto Smat, Elena Roseaux Mola, Osmara Lemagne Lugo, Ana Rosa Piñeiro Santana, Moraima Hernández Sáez, Mirian Pérez Frías, Jaime Lázaro Candelario Fuentes, Maria Yudith Monzón Rodríguez, Raúl Mederos Salgado, Lina Martínez Acosta, Sirsi Guilarte Díaz and Martha Bernal Pereira. - \$ M

\section{REFERENCES}

1. Gutiérrez B, Cavazza ME, Ortiz D, Correnti $M$, Vidal T, Mégraud F, et al. Seroprevalencia de la infección por Helicobacter pylori en pacientes con Gastritis Crónica, Úlcera Duodenal y Gástrica: Primer estudio de corte retrospectivo [Internet]. Rev Cubana Invest Bioméd. 2008 Apr-Jun [cited 2011 Jan 16];27(2). Available from: http://scielo.sld.cu/ scielo.php?script=sci_arttext\&pid=S086403002008000200011\&lng=es. Spanish.

2. Gutiérrez B, Vidal T, Valmaña CE, CamouJuncas C, Santos A, Mégraud F, et al. Infección por Helicobacter pylori en Ciudad de La Habana, Cuba. Prevalencia de las cepas cagA positivas [Internet]. Vaccimonitor. 2005 Jul-Dec [cited 2011 Jan 16];14(2):15-9. Available from: http://scielo. sld.cu/scielo.php?script=sci_arttext\&pid=S1025028X2005000200003\&lng=en. Spanish.

3. Wang YR, Richter JE, Dempsey DT. Trends and Outcomes of Hospitalizations for Peptic Ulcer Disease in the United States, 1993 to 2006 [Internet]. Ann Surg. 2010 [cited 2011 Jan 16];1:51-8. Available from: http://journals.Iww.com/annalsofsurgery/Abstract/2010/01000/Trends_and_Outcomes_of_Hospitalizations_for_Peptic.8.aspx

4. Montes Teves P, Salazar Ventura S, Monge Salgado E. Cambios en la Epidemiologia de la Úlcera Péptica y su Relación con la Infección con Helicobacter pylori. Hospital Daniel Carrion 2000-2005. Rev Gastroenterol Perú. 2007 Oct-Dec [cited 2011 Jan 16];27(4):382-8. Available from: http://www.scielo. org.pe/pdf/rgp/v27n4/a07v27n4.pdf. Spanish.
5. Piñol Jiménez F, Paniagua Estévez M. Cáncer gástrico: factores de riesgo [Internet]. Rev Cuba Oncol. 1998 Sep-Dec [cited 2011 Jan 16];14(3):171-9. Available from: http:// bases.bireme.br/cgi-bin/wxislind.exe/iah/ online/?IsisScript=iah/iah $. x i s \& s r c=g o o g l e \& b a s e$ =LILACS\&lang=p\&nextAction=Ink\&exprSearch= 299713\&indexSearch=ID. Spanish.

6. Luna Morales EC, Sierra Pérez DC, Gandul Salabarría L. La transformación del policlínico en Cuba de cara al siglo XXI [Internet]. Rev Cubana Med Gen Integr. 2009 Jul-Sep [cited 2011 Jan 16];25(2):1-10. Available from: http://scielo.sld. $\mathrm{cu} /$ scielo.php?script=sci_arttext\&pid=S086421252009000200016\&lng=es. Spanish.

7. Charles RJ, Cooper GS, Wong RC, Sivak MV Jr, Chak A. Effectiveness of open-access endoscopy in routine primary-care practice. Gastrointest Endosc. 2003 Feb;57(2):183-6

8. Smale S, Bjarnason I, Forgacs I, Prasad P, Mukhood $M$, Wong $M$, et al. Upper gastrointestinal endoscopy performed by nurses: scope for the future? Gut. 2003 Aug;52(8):1090-4.

9. Williams J, Russell I, Durai D, Cheung WY, Farrin A, Bloor K, et al. What are the clinical outcome and cost-effectiveness of endoscopy undertaken by nurses when compared with doctors? A MultiInstitution Nurse Endoscopy Trial (MINuET). Health Technol Assess. 2006 Oct;10(40):iii-iv, ix-x, 1-195.

10. Hernández Gómez LC. Presencia de la mujer en la Salud Pública Cubana [Internet]. Rev
Cub Salud Pública. 2009 Mar [cited 2011 Jan 16];35(1). Available from: http://www.scielosp. org/scielo.php?script=sci_arttext\&pid=S086434662009000100010\&lng=en. doi: 10.1590/ S0864-34662009000100010. Spanish.

11. Hernández Garcés HR. Manual de endoscopia digestiva superior diagnóstica. Havana: Editorial Ciencias Médicas; 2008. 232 p. Spanish.

12. Buesa F, Sotto A, Quintero M. Primer reporte del aislamiento de Campylobacter pyloridis en Cuba, 21 de marzo de 1986. Bol Epidemiol Hosp Doc Gen Calixto García. 1986;2:3. Spanish.

13. Mandado S, Gra B, González- Carvajal M Paniagua Piñol F, Domínguez C. Diagnóstico morfológico de Helicobacter pylori mediante citología gástrica por cepillado. Rev Cubana Med. 2003 Jan-Mar;42(1):27-33. Spanish.

14. Periles U. Tesis de Terminación de Residencia en Gastroenterología. Impacto de la Endoscopia Digestiva Superior en la Atención Primaria de Salud [thesis]. [Havana]: Facultad de Ciencias Médicas Calixto García Iñiguez; 2009.

15. Arús Soler E, Fábregas Rodríguez C, Haedo Quiñones W, Martínez López R, Nodarse Pérez $\mathrm{O}$, Ruiz Torres J, et al. Proyecciones de la Especialidad de Gastroenterología en Cuba para el 2015 [Internet]. Havana: Ministry of Public Health (CU); 2006 [cited 2011 Jan 16]. 28 p. Available from: http://www.sld.cu/galerias/pdf/sitios/gastroenterologia/informe_finala.pdf. Spanish.

16. Zuccaro G Jr, Provencher K. Does an open access system properly utilize endoscop- 
ic resources? Gastrointest Endosc. 1997 Jul;46(1):15-20.

17. Meaden C, Joshi M, Hollis S, Higham A, Lynch D. A Randomized Controlled Trial Comparing the Accuracy of General Diagnostic Upper Gastrointestinal Endoscopy Performed by Nurse or Medical Endoscopists. Endoscopy. 2006 Jun;38(6):553-60.

18. Sistema ProGastro [Internet]. [place unknown]: Rincón Grupo Sapiem; 2008. Available from: http://gruposapiem.wordpress.com/windowsapp/ sistema-progastro/. Spanish.

19. Gutiérrez B, Vidal T, Valmaña CE, Santiesteban N, González N, Leonard I, et al. Primer Informe sobre el Aislamiento de Helicobacter pylori asociado a enfermedades digestivas en Ciudad de La Habana. Vaccimonitor. 2001 JanMar;10(1). Spanish.

20. Camargo MC, Yepez MC, Ceron C, Guerrero N, Bravo LE, Correa P, et al. Age at Acquisition of Helicobacter pylori Infection: Comparison of Two Areas with Contrasting Risk of Gastric Cancer. Helicobacter. 2004 Jun;9(3):262-70.

21. González-Carbajal M, Rojas Zurita F, Grá Oramas B, Ávalos García R. Prevalencia de la infección por Helicobacter pylori en pacientes dispépticos. Rev Panam Infect. 2004;6(4):8-14. Spanish.

22. Aoki K, Kihaile PE, Wenyuan Z, Xianghang Z, Castro M, Disla M, et al. Comparison of Prevalence of Chronic Atrophic Gastritis in Japan, China, Tanzania, and the Dominican Republic. Ann Epidemiol. 2005 Sep;15(8):598-606.

23. Du J, Liu J, Zhang H, Yu CH, Li YM. Risk factors for gastroesophageal reflux disease, reflux esophagitis and non-erosive reflux disease among Chinese patients undergoing upper gastrointestinal endoscopic examination. World J Gastroenterol. 2007 Dec 7;13(45):6009-15.

24. Tseng PH, Lee YC, Chiu HM, Huang SP, Liao WC, Chen CC, et al. Prevalence and Clinical Characteristics of Barrett's Esophagus in a Chinese General Population. J Clin Gastroenterol. 2008 Nov-Dec;42(10):1074-9.
25. Kim N, Lee SW, Cho SI, Park CG, Yang HC, $\mathrm{Kim} \mathrm{HS}$, et al. The prevalence of and risk factors for erosive oesophagitis and non-erosive reflux disease: a nationwide multicentre prospective study in Korea. Aliment Pharmacol Ther. 2008 Jan;15;27(2):173-85.

26. Chen TS, Chang FY. The prevalence and risk factors of reflux esophagitis among adult Chinese population in Taiwan. J Clin Gastroenterol. 2007 Oct:41(9):819-22.

27. Aro P, Storskrubb T, Ronkainen J, Bolling-Sternevald E, Engstrand L, Vieth M, et al. Peptic Ulcer Disease in a General Adult Population: the Kalixanda Study: A Random Population-based Study. Am J Epidemiol. 2006 Jun 1;163(11):1025-34.

28. Voutilainen $M$, Mäntynen $T$, Färkkilä $M$, Juhola M, Sipponen P. Impact of Non-Steroidal AntiInflammatory Drug and Aspirin Use on the Prevalence of Dyspepsia and Uncomplicated Peptic Ulcer Disease. Scand J Gastroenterol. 2001 Aug;36(8):817-21.

29. Abahussain EA, Hasan FA, Nicholls PJ. Dyspepsia and Helicobacter pylori infection: Analysis of 200 Kuwaiti patients referred for endoscopy. Ann Saudi Med. 1998 Nov-Dec;18(6):502-5.

30. Sacco F, Bruce MG, McMahon BJ, Bruden D. A prospective evaluation of 200 upper endoscopies performed in Alaska Native persons. Int J Circumpolar Health. 2007 Apr;66(2):144-52.

31. Li Z, Zou D, Ma X, Chen J, Shi X, Gong Y, et al. Epidemiology of Peptic Ulcer Disease: Endoscopic Results of the Systematic Investigation of Gastrointestinal Disease in China. Am J Gastroenterol. 2010 Dec;105(12):2570-7.

32. Konturek SJ, Bielański W, Płonka M, Pawlik T, Pepera J, Konturek PC, et al. Helicobacter pylori, non-steroidal anti-inflammatory drugs and smoking in risk pattern of gastroduodenal ulcers. Scand J Gastroenterol. 2003 Sep;38(9):923-30.

33. Halter F, Brignoli R. Helicobacter pylori and smoking: two additive risk factors for organic dyspepsia. Yale J Biol Med. 1998 Mar-Apr;71(2):91-9.

34. Weck MN, Brenner H. Association of Helicobacter pylori infection with chronic atrophic gastritis:
Meta-analyses according to type of disease definition. Int J Cancer. 2008 Aug 15;123(4):874-81.

35. Moshkowitz M, Brill S, Konikoff FM, Averbuch $\mathrm{M}$, Arber N, Halpern Z. Additive deleterious effect of smoking on gastroduodenal pathology and clinical course in Helicobacter pylori-positive dyspeptic patients. Isr Med Assoc J. 2000 Dec;2(12):892-5.

36. Schubert TT, Bologna SD, Nensey $Y$, Schubert $A B$, Mascha EJ, Ma CK. Ulcer risk factors: interactions between Helicobacter pylori infection, nonsteroidal use, and age. Am J Med. 1993 Apr;94(4):413-8.

37. Yamada M, Wong FL, Fujiwara S, Tatsukawa $Y$, Suzuki G. Smoking and alcohol habits as risk factors for benign digestive diseases in a Japanese population: the radiation effects research foundation adult health study. Digestion. $2005 ; 71(4): 231-7$

\section{THE AUTHORS}

Enrique Galbán García (Corresponding author: galban@infomed.sld.cu),physician specializing in epidemiology with a doctorate in public health. Chief of epidemiology, National Gastroenterology Institute (IGE), Havana, Cuba.

Enrique Arús Soler, gastroenterologist with a doctorate in medical sciences. Director, IGE, Havana, Cuba.

Ulises Periles Gordillo, gastroenterologist, IGE, Havana, Cuba.

Submitted: October 14, 2010

Approved for publication: January 10, 2012 Disclosures: None

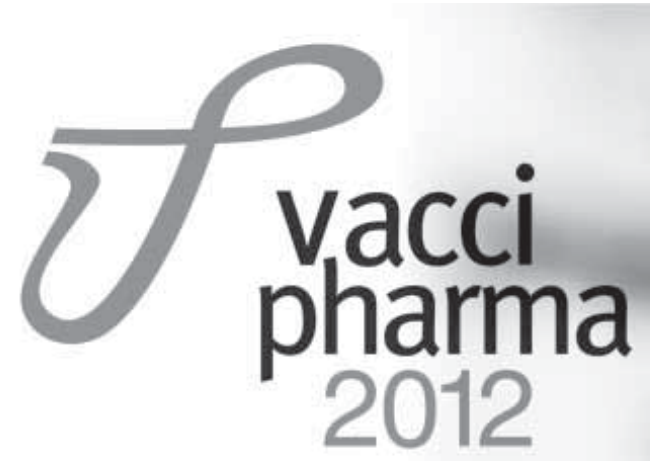

Second International Congress on the Pharmacology of Vaccines June 16-20, 2012 Barceló Cayo Santa Maria Hotel Cayo Santa María, Villa Clara, Cuba

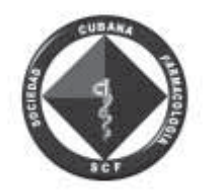

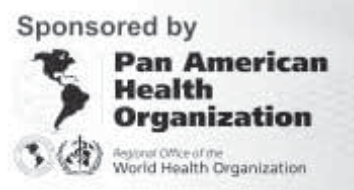

The Cuban Society of Pharmacology invites you to VacciPharma 2012 to learn about the latest developments in human and veterinary vaccines, exchange experiences with other experts and help accelerate progress in vaccine development.

Three workshops will be offered:

- Prophylactic vaccines

- New technologies in prophylactic vaccine development

- Therapeutic vaccines

Related events:

- Symposium on veterinary vaccines

- Regional meeting on DTP/HB/Hib/IPV combined vaccine
Rolando Ochoa Azze MD vaccipharma@finlay.edu.cu 